\title{
The storage of bed material in mountain stream channels as assessed using Optically Stimulated Luminescence dating
}

\author{
Chris Thompson ${ }^{\mathrm{a}, *}$, Ed Rhodes ${ }^{\mathrm{b}}$, Jacky Croke $^{\mathrm{a}}$ \\ a School of Physical, Environmental and Mathematical Sciences, UNSW@ADFA, Northcott Drive, Canberra, ACT 2601, Australia \\ ${ }^{\mathrm{b}}$ Research School of Earth Sciences and Research School of Asian and Pacific Studies. The Australian National University, \\ Canberra, ACT 0200, Australia
}

Accepted 13 February 2006

Available online 9 June 2006

\begin{abstract}
A detailed understanding of channel forming and maintenance processes in mountain streams requires some measurement and/ or prediction of bed load transport and sediment mobility. Traditional field based measurements of such processes are problematic because of the high formative discharges characteristic of such streams. The application of Optically Stimulated Luminescence (OSL) dating is proposed here as a new way of determining actual residency times of fine sediments and consequently validating selected predictions for the entrainment of sediment in these streams. Model predictions of sediment mobility for selected step-pool and plane-bed channels in a mountain catchment in south eastern Australia are initially calculated using equations of hydraulic competence and the one-dimensional HEC-RAS model. Results indicate that floods exceeding bankfull with recurrence intervals up to 13 years are competent to mobilise the maximum overlying surface grain sizes at both sites. OSL minimum age model results from 7 samples of well bleached quartz in the fine matrix particles indicate general agreement with selected competence equations. The apparent long (100-1400 y) burial age of most of the mineral quartz, however, suggests that competent flows are not able to flush all subsurface fine-bed material. The depth of maximum bed load exchange (flushing) was limited to $\leq$ twice the depth of the overlying $D_{90}$ grain size. Application of OSL in this study provides important insight into the nature of storage and flushing of matrix material in mountain streams.
\end{abstract}

(C) 2006 Elsevier B.V. All rights reserved.

Keywords: Mountain streams; Bedload transport; Sediment mobility; Optically Stimulated Luminescence dating

\section{Introduction}

A detailed understanding of channel forming and maintenance processes in mountain streams requires some measurement and/or prediction of the mobility of sediment as it relates to floods of varying magnitude and

\footnotetext{
* Corresponding author. Tel.: +61 2 62688317; fax: +61 2 62688687.

E-mail address: C.Thompson@adfa.edu.au (C. Thompson).
}

frequency (Lenzi et al., 2004). Of particular relevance to the maintenance of coarse-bed channels is the interaction between mobility rates of surface and subsurface sediments (Wilcock et al., 1996a; Wilcock and McArdell, 1997). The release of subsurface fine-bed material, or flushing, occurs when surface armour grains are entrained, a state referred to as Phase II bed load transport (Jackson and Beschta, 1982; Wilcock et al., 1996a). Phase II transport includes the full mobility of the small grain sizes and partial transport of larger bed grains (e.g. 
Fig. 1). Recent studies in mountain rivers have shown that cobbles and boulders are selectively (or partially) transported during high magnitude floods whereas smaller grains may undergo full mobility (Haschenburger and Wilcock, 2003; Lenzi et al., 2004). For gravel-bed channels, Phase II commences at between $60-100 \%$ of bankfull discharge $\left(Q_{\mathrm{bf}}\right)$ (Ryan et al., 2002), but in channels with increased boundary resistance, such as some mountain channels, the onset of Phase II has been considered either unrelated to, or exceeding, bankfull flows (Carling, 1988; Emmett and Wolman, 2001). More recent studies suggest that a change from Phase I to II occurs between $60-100 \%$ bankfull flow irrespective of channel type and boundary resistance (Ryan et al., 2005).

Traditional methods of determining the degree of armour break up and depth of bed material flushing include the use of scour chains and monitors (Laronne et al., 1994; DeVries, 2002) and buried tracer particles
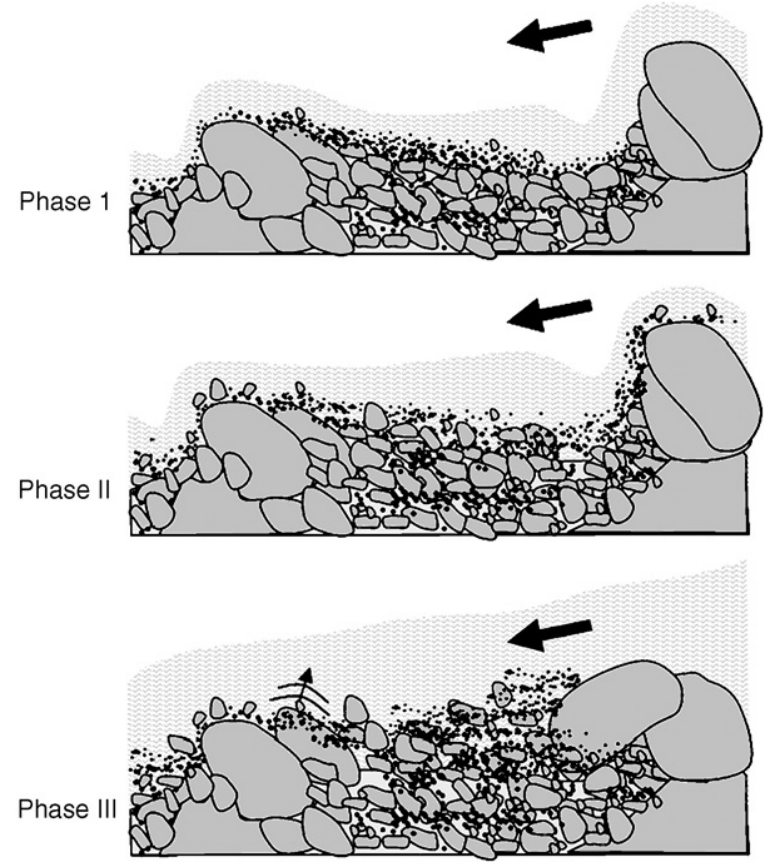

Fig. 1. The 3 Phases of bedload transport (after Warburton, 1992). Phase I, surface fines (sand-pebbles) entrained with occasional cobble from surface armour but, generally armour protects subsurface sediment from entrainment. Discharge $\leq 0.6 Q_{\mathrm{bf}}$. Phase II represents the movement and entrainment of a proportion of coarse armour grains (up to $D_{90}$ ) which provides sites for subsurface sediment to be transported. Phase II commencement observed as a rapid increase in the rate of bedload transport as subsurface sediment is released. Smaller grains tend to be in full mobility while the coarsest grains are subject to partial transport. Discharge $\geq 0.6 Q_{\mathrm{bf}}$ to $Q_{\mathrm{bf}}$. Phase III represents the full mobility of surface armour and other surface structures that generally provide bed stability. Excess shear stress is $\geq 4.5$. Steps are broken and reformed. Subsurface sediment is reworked.
(Wilcock et al., 1996b). These data have typically been collected from pool-riffle and plane-bed reaches and generally support the conclusions of flume studies, which suggest that once relatively high shear stresses are reached and armour is mobilised, flushing approaches a maximum depth of approximately twice the thickness of the armour layer (Wilcock and McArdell, 1997). Because of logistical difficulties in the collection of field data under the extreme flood discharges required to initiate mobility of the bed surface, few studies can draw upon sufficiently long periods of data collection to determine the extent of bed flushing and related discharges across the range of types of mountain channels.

In part to compensate for such difficulties, equations for empirical flow competence (e.g. Komar, 1989) have been developed to predict the mobility of armour and bedform stabilising grains. These equations have been applied to individual reaches to predict the occurrence of Phase II transport based on the entrainment of a threshold grain size (e.g. Olsen et al., 1997) and the vertical extent of flushing (e.g. DeVries, 2002). In cobble- and boulder-bed channels the threshold grain size relates to the size of the bedform stabilising grains (e.g. $D_{84}, D_{90}$ ) (Grant et al., 1990; Church et al., 1998). This then allows some prediction of when transport of the matrix material occurs (Wilcock et al., 1996a). Understandably, given the heterogenous nature of grain sizes, shape and packing in mountain rivers, all interacting with variable flow frequencies, magnitude and duration, different competence or entrainment equations have produced quite variable results (e.g. Petit, 1994; Petit et al., 2005).

The application of Optically Stimulated Luminescence (OSL) dating is considered here as an alternative and innovative way to determine the residency times of fine sediment in mountain streams. Estimates of age, derived with this technique, are used to assist in calibrating models of sediment entrainment to specific channel types and hydrological regimes. The objective of this research, therefore, is twofold. Firstly, we aim to characterize the competence of two mountain channel morphologies using relationships for sediment transport entrainment and to use these predictions to determine the residency of subsurface fine-grained material. Secondly, we seek to explore the application of OSL to deriving meaningful burial ages for the fine material in these two reaches and to compare results with model predictions. To our knowledge, this is the first application of the technique for determining the residency times of matrix materials in mountain streams. As such, we exploit the opportunity to investigate, and report on, the suitability of the technique for the type of sediment transport conditions characteristic of mountain streams. We 
undertake additional sampling and laboratory analyses to assess the basic assumptions of OSL signal zeroing of quartz grains to ensure that the method is appropriate to the research question and geomorphic conditions addressed in this study.

To meet these objectives, we have selected two sites with contrasting channel morphologies with the expectation that reach morphology, as determined largely by the protrusion of large immobile grains forming a discrete bedform, will exert some influence upon the rates of sediment mobility and hence on the residency time of fine sediment in the matrix material.

\section{Study area}

The study was conducted within Log Culvert Creek catchment, which has an area of $7.7 \mathrm{~km}^{2}$ and is located in the headwaters of the Genoa River in south eastern Australia (Fig. 2). Channel types include pool-riffle, plane-bed and step-pool (Buffington and Montgomery, 1997). The climate is warm-temperate, with uniform rainfall averaging $1011 \mathrm{~mm}$ per annum (Craigie, Station No. 070326). The elevation of the catchment divide is $973 \mathrm{~m}$ asl and the study reaches are located at approximately $783 \mathrm{~m}$ asl. Snowfalls occur during winter but a snow pack does not form. The catchment is underlain by Ordovician Metasediments which weather to form disc and blade shaped grains. Quartz is a dominant mineral of the lithology with smaller amounts of feldspar (Reinson, 1977). Land use within Log Culvert catchment is plantation forestry (Pinus radiata), established from 1971 to 1987. Native forest harvesting occurred prior to plantation establishment. Native vegetation buffers have been retained around the stream.

\subsection{Flow history}

Like surrounding rivers, the Genoa River has high variability in inter-annual discharge. In February 1971 a flood with a 100 year average recurrence interval occurred on the Genoa River and was reported as the largest flood since European settlement (Erskine, 1993). Downstream

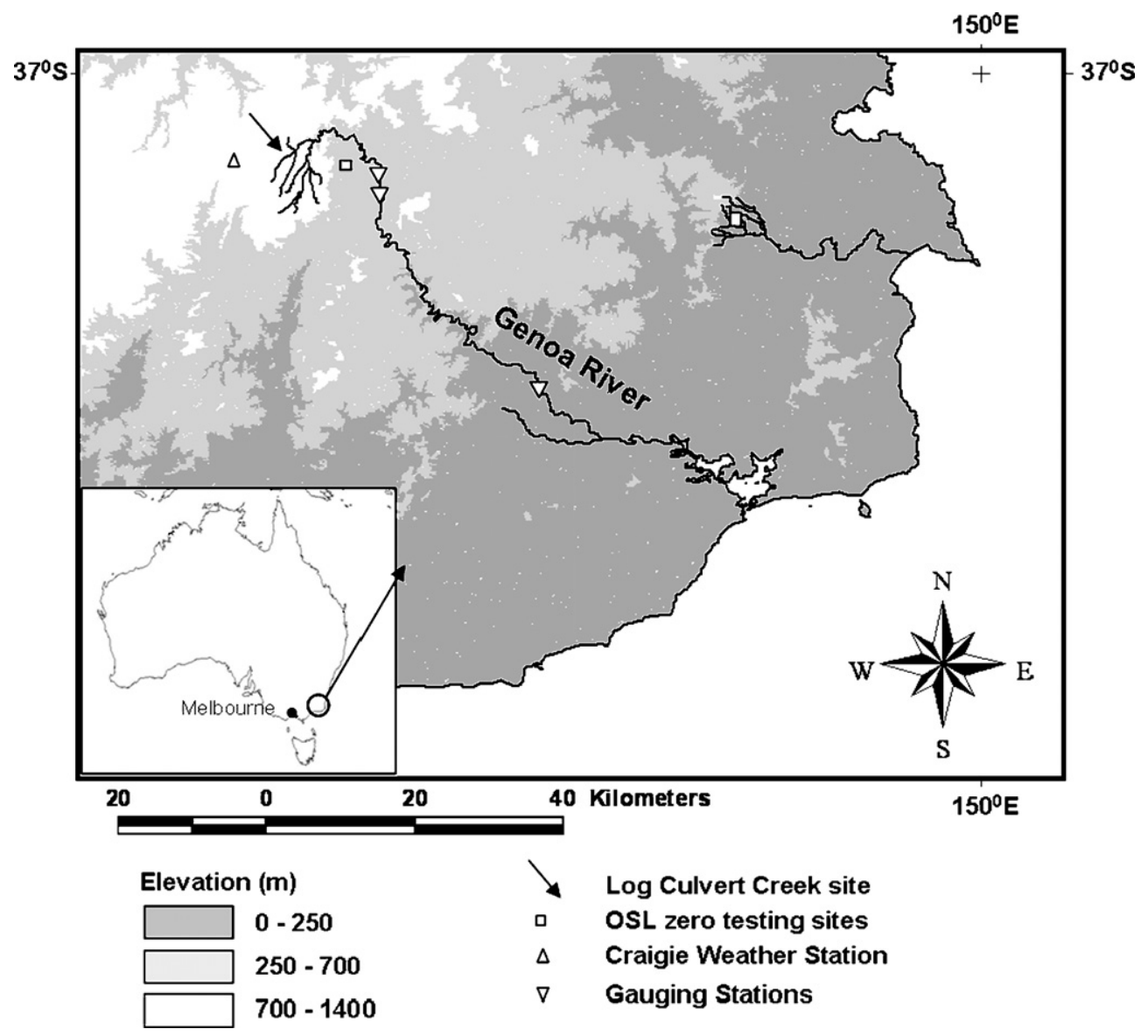

Fig. 2. Study location in SE Australia. 


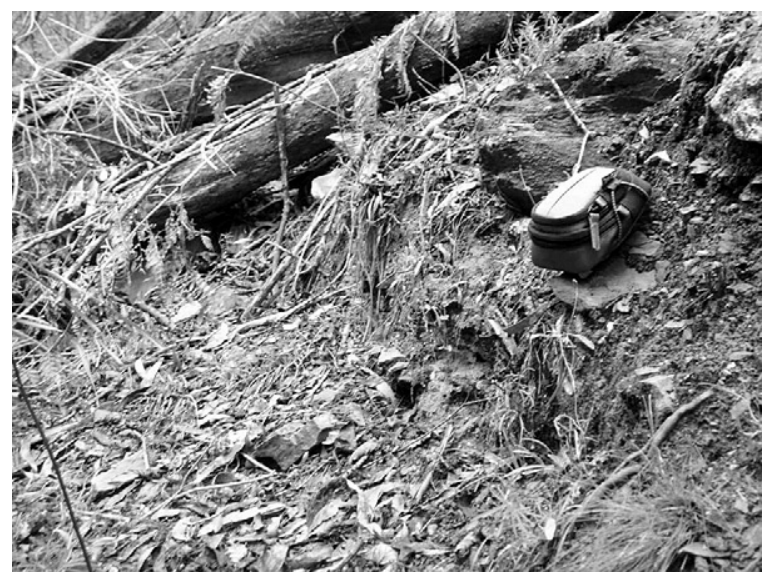

Fig. 3. Photo showing the scour/slough line at XS 14 that marks the height of the 1971 flood. Digital camera case included for scale.

gauging stations at Rockton (Area $=120.35 \mathrm{~km}^{2}$ ) and Big Flat Creek Junction (Area $=829 \mathrm{~km}^{2}$ ) recorded unit discharges of $5 \mathrm{~m}^{3} \mathrm{~s}^{-1} \mathrm{~km}^{-2}$ and $3.15 \mathrm{~m}^{3} \mathrm{~s}^{-1} \mathrm{~km}^{-2}$ respectively for the event. Rainfall records (1930-2005) from Craigie show February 1971 as having the highest monthly rainfall.

No gauging stations are located higher in Log Culvert Creek and no preserved evidence exists in the form of flood rack, slackwater deposits or tree scaring in the study channel from the 1971 flood. An intermittent scour/ slough line, however, is present along the right hillslope, $2.35 \mathrm{~m}$ above the thalweg and provides a water surface level indicator for the flood (Fig. 3). The peak discharge for the 1971 peak flood at the study channel was estimated by a catchment scaling equation (Gordon et al., 2004) using 100 year average recurrence interval discharges from 3 downstream gauges (Rockton, $120.35 \mathrm{~km}^{2}$; Bondi, $235 \mathrm{~km}^{2}$; Big Flat Ck Junction, $829 \mathrm{~km}^{2}$ ). This was compared with a simulated prediction from HEC-RAS 3.1.1 (US Army Corps of Engineers, 2003) which was used to route various discharges through surveyed cross-sections until a water surface profile matched the elevation of the flood indicator. Both methods estimated a discharge of $78.1 \mathrm{~m}^{3} \mathrm{~s}^{-1}$.

The period subsequent to the 1971 flood has been dominated by smaller floods and drought. Downstream gauge records (Rockton) and top of catchment rainfall records (Craigie) indicate that in the past 10 years, Log Culvert Creek received minor floods $\left(\geq Q_{\mathrm{bf}}\right)$ in November 1995, June 1998, March 2000 and February 2002. The discharges for these events were estimated by scaling from the Rockton gauging station (Table 2). The largest of these flows (March 2000) had a 13 year average recurrence interval at the Rockton gauging station. Drought has persisted from February 2002 to June 2005 with little or no surface flow during the time OSL sampling was conducted.

\section{Methods}

A $100 \mathrm{~m}$ section of Log Culvert Creek was selected (Fig. 4a) for analysis. Within this section, a 20-m steppool reach grades into plane-bed (Figs. $4 \mathrm{~b}$ and 5). Contiguous reaches were selected to minimise variability in discharge, sediment supply, flood history and OSL characteristics. No notable point sources of sediment, such as landslides, debris flows or road stream crossings, are near these reaches. Consequently, the step-pool and plane-bed sites are believed to have similar supply conditions for sediment. Volumetric samples of surface grains were taken at each sample location to identify the range of grain sizes that would need to be mobilised to allow exchange of matrix material. Samples were sieved and weighed in $0.5 \psi\left(\log _{2}\right)$ intervals to construct cumulative

(a)

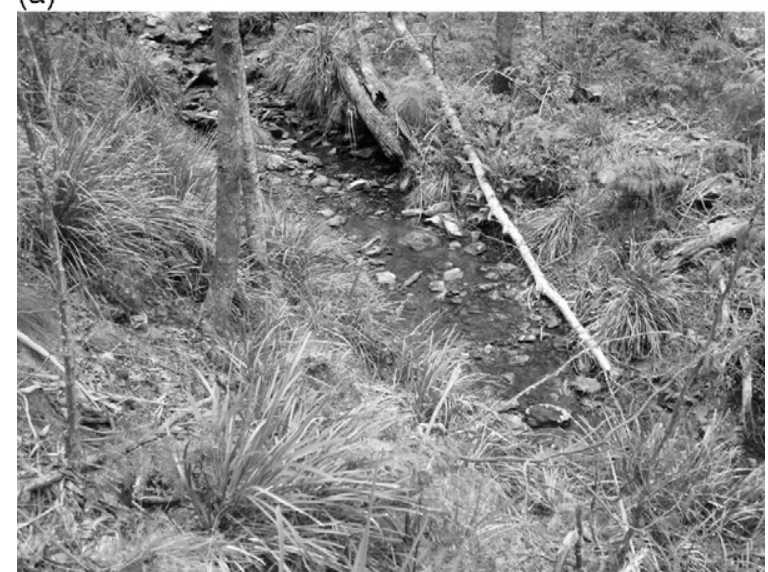

(b)

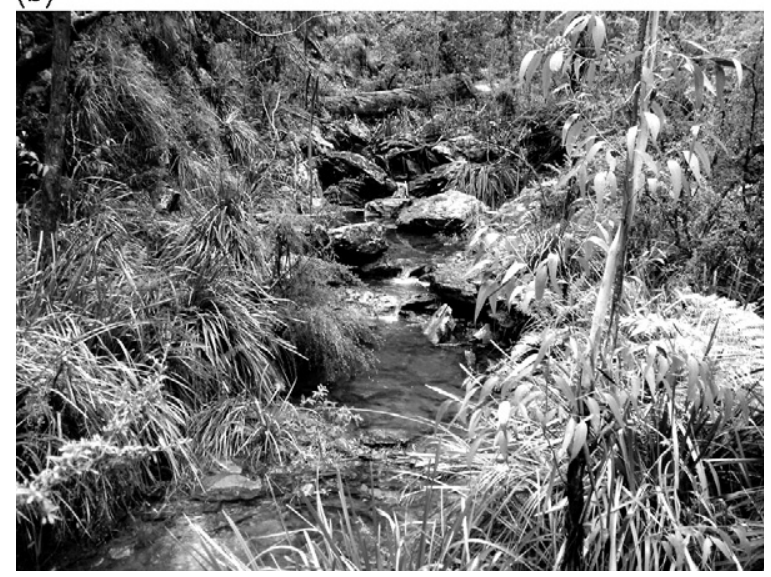

Fig. 4. Site photos looking upstream at (a) the plane-bed and (b) steppool sample reaches. 


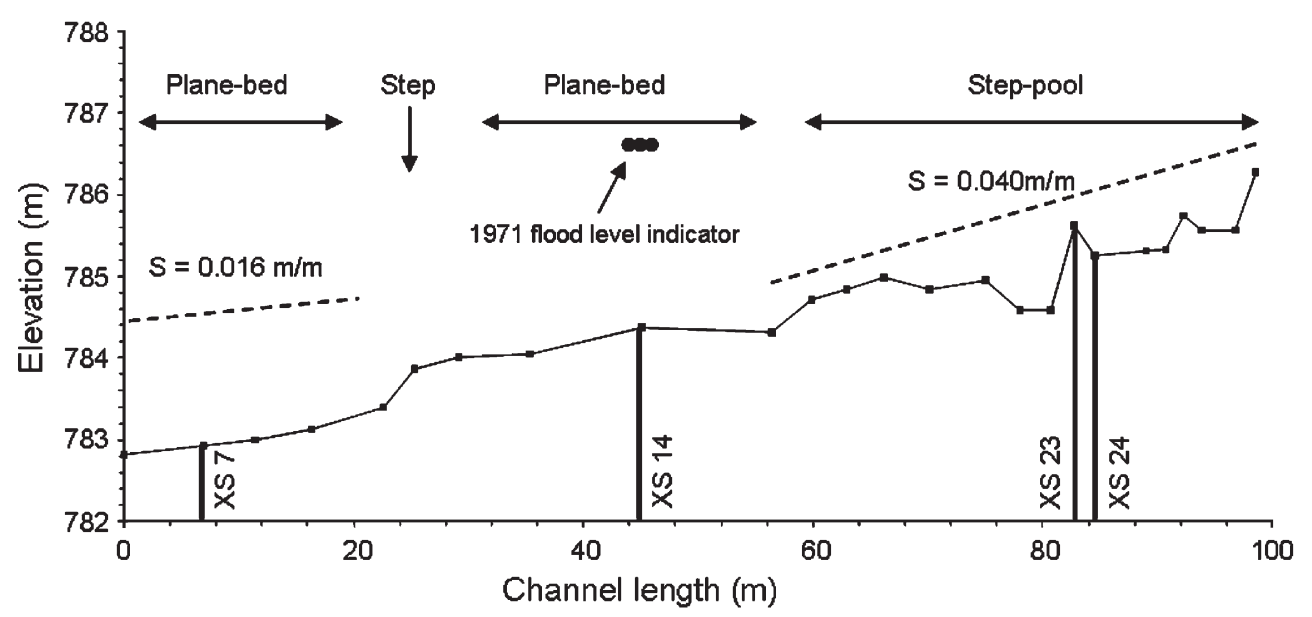

Fig. 5. The longitudinal profile of the study channel showing the step-pool and plane-bed morphology. OSL samples P1 and P2 are taken at XS 7, S1 and S2 at XS 24 and associated boulder step is at XS 23. The only preserved flood indicator (bank scour lines) along the channel, which is used as the maximum water surface of the 1971 flood (100 year ARI.), occurs at XS 14.

probability distributions to obtain median grain sizes $\left(D_{50}\right) . D_{\max }$ is defined here as the mean of the largest 5 grains from the volumetric sample measured by calipers. A tape was used to measure the $b$-axis of the five largest step forming grains in situ to determine step $D_{\max }$. This value is considered to represent the clast size needed to be entrained to mobilize step-pool sequences (Chin, 1998).

\subsection{Competence}

This study employs Komar's (1989) selective entrainment equation (Eq. (1)) to determine the critical shear stress $\left(\tau_{\mathrm{c}}\right)$ required to mobilise the $D_{\max }$ overlying each OSL sample and the boulder step downstream of the OSL step samples.

$\tau_{c}=\tau^{*}{ }_{\mathrm{c} 50}\left(\rho_{s}-\rho\right) g D_{50}^{b} D_{\max }^{1-b}\left(\mathrm{Nm}^{-2}\right)$

where $\tau^{*}{ }_{\mathrm{c} 50}$ is a dimensionless critical shear stress for the entrainment of the $D_{50}, \rho_{\mathrm{s}}=$ density of the grains and $\rho=$ the density of water where $\rho_{\mathrm{s}}-\rho=1650 \mathrm{~kg} \mathrm{~m}^{-3}$, g is the gravitational force and $b$ is a hiding factor used to adjust $\tau *{ }_{\text {c50 }}$ based on the relative grain size or exposure of the $D_{\max } . b$ is set to 0.6 (Komar, 1989) for each of the OSL sampling localities. For the boulder step, where similar sized boulders lie imbricated against each other, $b$ is set to 0 and the equation takes the form of the original Shields equation.

$\tau^{*}{ }_{c 50}$ is known to vary with channel bed characteristics, such as grain shape, orientation and packing, but is generally assigned a value of $0.03-0.045$ for loosely packed natural beds (Komar, 1989; Buffington and Montgomery, 1997). Beds comprised of disc and blade grains, as is the case in Log Culvert Creek, tend to pack more tightly and develop more resistant bed armour (Laronne and Carson, 1976; Komar and Li, 1986). Therefore, a higher $\tau^{*}{ }_{\mathrm{c} 50}$ of 0.06 is used, a value previously used for the assessment of channel competence (Zimmermann and Church, 2001; Young et al., 2002).

\subsection{Channel hydraulics}

Twenty five cross-sections (XS) were surveyed by Total Station along the channel (Fig. 5). These channel geometry data are used for one-dimensional stepbackwater hydraulic modelling to determine channel boundary shear stresses for the two reaches and associated boulder steps. One-dimensional step-backwater models are not easy to use in mountain streams because the assumptions are difficult to meet, but, short of a better alternative, they have produced good estimates of channel hydraulics for step-pool channels, especially at high flows (Chin, 2003). HEC-RAS 3.1.1, therefore, was used with contraction and expansion coefficients set to 0.1 and 0.3 respectively. The downstream boundary condition was set to normal depth (0.016), upstream boundary condition set to critical depth and the model was computed for a mixed (sub- and supercritical) flow regime. A Manning's $n$ was determined for the plane-bed and step-pool channel for each discharge by averaging $n$ calculated by the method of Jarrett (1984)

$n=0.32 S^{0.38} R^{-0.16}$

and Limerinos (1970)

$n=0.0926 R^{0.17} /\left(1.16+2 \log \left(R / D_{84}\right)\right)$ 


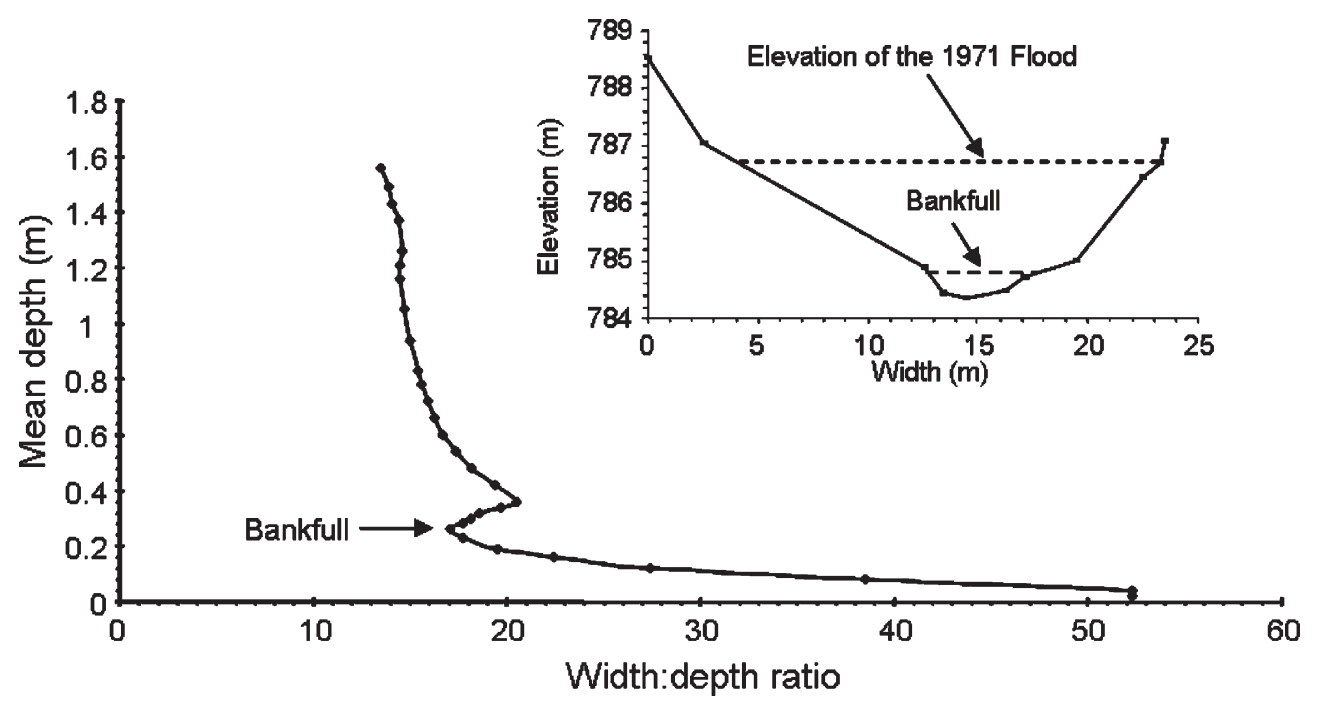

Fig. 6. Width/depth ratio plotted against depth for various flow stages. Bankfull is determined by the break in curve (as marked) which yields a crosssectional geometry as shown by the inset figure. Inset figure also shows the elevation of the 1971 flood as indicated by the height of the scour/slough line.

where $S$ is channel slope, $R$ is hydraulic radius and $D_{84}$ is the grain size that $84 \%$ of channel grains are finer than.

\subsubsection{Bankfull discharge}

To determine if $Q_{\mathrm{bf}}$ is competent to initiate Phase II transport, bankfull geometry was defined and $Q_{\mathrm{bf}}$ was then determined by routing various discharges through the cross-sections using HEC-RAS to find the flow which best matched the elevation of the bankfull water surface. Two methods provided bankfull geometry and water surface levels. In the field, bank tops were defined by perennial riparian vegetation and the height of lichen on large boulders/bedrock in the channel. Secondly, width to depth ratios $(w / d)$ were calculated and plotted against mean depth. Whereas the $w / d$ ratio did not approach a minimum within the surveyed cross-section (cf Carling, 1988), the occurrence of a break in curve indicated bankfull geometry that agreed with field observations (Fig. 6).

\subsection{OSL dating methods}

OSL dating involves the measurement of a luminescence emission which reflects the concentration of charge trapped within the crystalline lattice of quartz and feldspar minerals (Wallinga, 2002). The charge accumulates whenever a mineral grain is buried and the time since it was last exposed to light can be calculated by determining the total accumulated charge (equivalent dose, $D_{\mathrm{e}}$ ) and dividing this value by the calculated rate of ionizing radiation rate or annual dose (Aitken, 1985).

\subsubsection{Sample design}

Two replicate OSL samples were taken at XS 7 (Fig. 5) in the plane-bed channel (P1, P2; Fig 7a) and two at XS 24 (Fig. 5) in the pool area of the step-pool reach (S1, S2 Fig. 7). Replicates were sampled approximately $1 \mathrm{~m}$ apart in the centre of the channel and from beneath similar surface grain sizes (Fig. 8). Each sample (excluding S2) was sampled at two depths which were defined by the length of the $b$-axis of the overlying surface $D_{90}$ grain size $(\sim 150 \mathrm{~mm}$, Fig. 7a). The shallow sample (i.e. S1S) was taken from beneath the armour layer and the deep sample (i.e. S1D) taken from below twice the $D_{90}$ depth to determine the depth of disturbance of the bed load (Table 1). No deep sample was taken at $S 2$ because of sampling difficulties with freeze core equipment. Thus, samples at

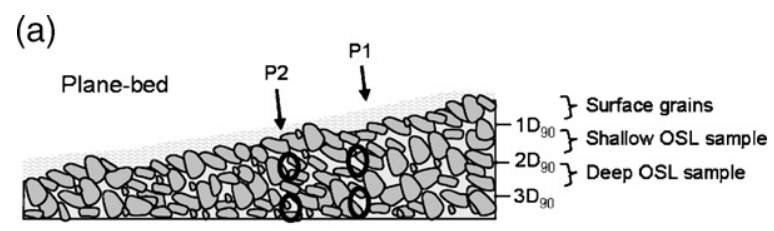

(b)

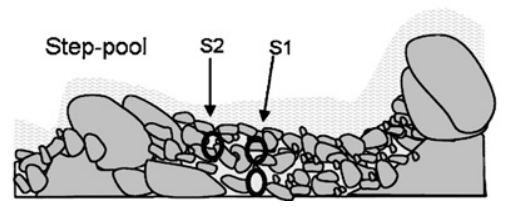

Fig. 7. Experimental design for OSL sampling in (a) the plane-bed at XS 7 and (b) step-pool at XS 24. The scale on the right side of (a) is in units representing the length of the $b$-axis of the overlying $D_{90}$ grain size $(\sim 150 \mathrm{~mm})$. 


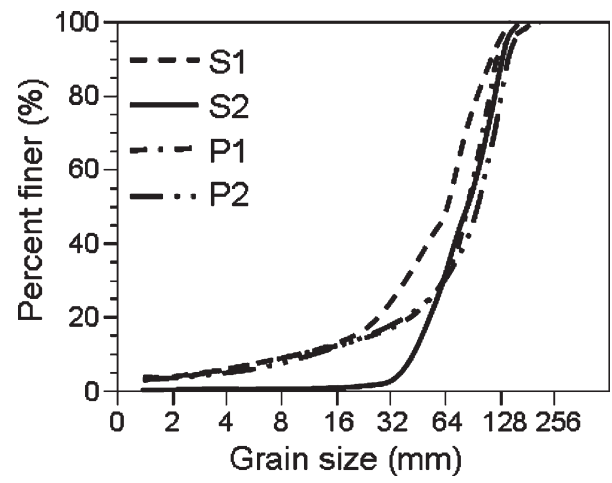

Fig. 8. Distributions of surface grain sizes sampled from above OSL sample sites. A volumetric sampling method was used and grains were sieved and weighed in $0.5 \psi$ size classes.

three step-pool sites and four plane-bed locations provided the sediments for OSL dating. The total number of sediment samples ( 7 sites by 48 single grain ages) analysed in this study is comparable to that reported in other studies using similar techniques (e.g. Olley et al., 1998; Fuchs and Lang, 2001; Spencer and Owen, 2004; Rodnight et al., 2005).

\subsubsection{OSL sample collection}

OSL sampling was conducted at night with torches covered by red 106 celluloid filter. Flow at the time of sampling was $300 \mathrm{~mm}$ below the bed surface. The dry bed surface was spray-painted then removed to the sampling depth where fine-bed material was collected. Deep samples were recovered using a freeze coring technique to prevent surface grain contamination in the wet unconsolidated medium. This entailed dispensing liquid $\mathrm{CO}_{2}$ into a stand pipe inserted into the channel bed, which froze surrounding water and grains to the stand pipe. The stand pipe was then extracted with up to $10 \mathrm{~kg}$ of subsurface material attached for OSL sampling at the desired depth. Samples were sealed in light proof containers and immediately transferred to the laboratory. The annual dose of radiation was measured in situ using a portable $\mathrm{NaI}$ gamma spectrometer probe inserted into the bed sampling holes.

\subsubsection{Natural zeroing and dose recovery of modern in channel flood deposits}

To determine the suitability of single grains for this application of OSL dating, in particular with respect to thermal transfer and partial bleaching, bed load material from two Birkbeck-slot traps in two nearby instrumented catchments were analysed (see Fig. 2). The Birkbeckslot traps contained sediment up to $100 \mathrm{~mm}$ in size, from an event in December 2004 which had a 2-3 year recurrence interval. The first trap in Oldroad Creek shares similar catchment area, lithology and channel confinement characteristics to that of Log Culvert Creek. The second trap was located in an un-named catchment which overlies a granite lithology and has a smaller catchment area $\left(3 \mathrm{~km}^{2}\right)$ than that of the study area. No flows capable of transporting bed load have occurred in Log Culvert Creek between bed load trap installation 3 years ago and OSL sampling for this study.

The bed load material was sampled by spray painting the surface grains and then removing all painted grains under dim red lighting during darkness. The remaining subsurface sediment was placed into black plastic bags and returned to the laboratory to isolate quartz grains. Sediment samples from these traps are herein referred to as 'modern' and assigned processing codes of K0382 and K0384, respectively.

\subsubsection{Laboratory analyses}

Standard OSL procedures for each sample are used to prepare sand sized quartz grains measuring 180$212 \mu \mathrm{m}$ under laboratory lighting conditions (Rhodes, 1988). For these samples, specific steps included wet sieving to isolate the selected grain size, treatment with dilute $\mathrm{HCl}$ to remove carbonate, etching for $100 \mathrm{~min}$ in concentrated $(40 \%)$ HF. Following the etching treatment, heavy minerals are removed using a sodium polytungstate solution with a density of $2.68 \mathrm{gcm}^{-3}$, and after drying, the material was re-sieved to remove grains $<180 \mu \mathrm{m}$. Grains are mounted on stainless steel discs using silicone oil for OSL measurement.

\subsubsection{OSL measurement}

All OSL measurements were made at $125^{\circ} \mathrm{C}$ using the single aliquot regenerative-dose (SAR) protocol of

Table 1

OSL sample characteristics

\begin{tabular}{lllll}
$\begin{array}{l}\text { a Sample } \\
\text { code }\end{array}$ & $\begin{array}{l}{ }^{\mathrm{b}} \text { Surface } \\
D_{\max }(\mathrm{mm})\end{array}$ & $\begin{array}{l}\text { Surface } D_{90} \\
(\mathrm{~mm})\end{array}$ & $\begin{array}{l}\text { Surface } D_{50} \\
(\mathrm{~mm})\end{array}$ & $\begin{array}{l}\text { Sample } \\
\text { depth }(\mathrm{mm})\end{array}$ \\
\hline P1S & 164 & 130 & 86 & $150-300$ \\
P1D & 164 & 130 & 86 & $350-500$ \\
P2S & 163 & 142 & 96 & $150-300$ \\
P2D & 163 & 142 & 96 & $350-500$ \\
S1S & 133 & 116 & 66 & $150-300$ \\
S1D & 133 & 116 & 66 & $350-500$ \\
S2S & 151 & 140 & 87 & $150-300$ \\
'Step & 1000 & - & - & n.a. \\
\hline
\end{tabular}

${ }^{\text {a }}$ Prefix P and S refer to planebed and step-pool respectively and D and $\mathrm{S}$ refer to shallow sample and deep sample respectively.

${ }^{\mathrm{b}} D_{\max }$ refers to the average diameter of the 5 largest grains.

c Step included for competence assessment because of its potential role in constraining upstream sediments. 
Murray and Wintle (2000), incorporating an additional IRSL wash at $60{ }^{\circ} \mathrm{C}$ before each OSL measurement to improve the purity of the quartz OSL emission (Banerjee et al., 2001). Because Rhodes (2000) demonstrated that, for some immature fluvial sediments, higher temperature preheating can induce large unwanted OSL signals, preheat conditions of $10 \mathrm{~s}$ at $220{ }^{\circ} \mathrm{C}$ were selected for preheat 1 of each cycle, immediately prior to the measurement of the natural and regenerated OSL signals, and $10 \mathrm{~s}$ at $200{ }^{\circ} \mathrm{C}$ for preheat 2 , prior to the measurement of each test-dose OSL response. These conditions duplicate those of Rhodes et al. (2003), who achieved high precision and accuracy for young archaeological sediments.

Estimates of the palaeodose (the dose that the sample was exposed to during burial) were also validated using a recovered dose experiment. Single grains from the modern sample K0384 were exposed to $5 \mathrm{~min}$ of daylight, avoiding direct sunlight exposure, at around $580 \mathrm{~m}$ asl, $34^{\circ} \mathrm{S}, 10.00$ a.m. on a clear March day. Subsequently, these grains were given a beta dose of $1.99 \mathrm{~Gy}$, corresponding to an age of approximately 660 years. A single grain SAR protocol, similar to that used to determine the estimates of age was used to measure this administered dose.

\subsubsection{OSL age determination}

Distributions of single grain ages were measured for the step-pool and plane-bed samples, and the environmental dose rate based on in-situ MCA-465 NaI gamma spectrometer measurements of $\mathrm{U}, \mathrm{Th}$, and $\mathrm{K}$, and total gamma dose rate. Grain-size attenuation of beta dose rates was based on the values of Mejdahl (1979), water attenuation following that outlined in Aitken (1985), and the energy conversion factors of Adamiec and Aitken (1988) were used. Contributions of the cosmic dose rate were calculated using the formulae of Prescott and Hutton (1994). For the modern samples, an estimated value of total dose rate of $3 \mathrm{mGya}^{-1}$ has been used to plot the results of $D_{\mathrm{e}}$ distributions in a more accessible form.
To determine the youngest population of quartz grains within each sample, the model of minimum age (Galbraith et al., 1999) was applied. This statistical model has been shown to return accurate burial ages for partially bleached grains and ages equal to the standard central age model for well bleached grains (Olley et al., 2004).

\section{Results}

\subsection{Hydraulics and competence}

Table 2 outlines the average and range of estimated discharges, with the respective water surface profiles illustrated in Fig. 9a. A range in bankfull discharge $\left(Q_{\mathrm{bf}}\right)$ is given to accommodate variability in bankfull geometry along the study channel. Fig. $9 \mathrm{~b}$ represents the variability in boundary shear stress between cross-sections and recurrence interval discharges. Froude numbers remain below critical for all modelled discharges except at XS 11 and XS 23, where supercritical flows persist. For flows up to $6.7 \mathrm{~m}^{3} \mathrm{~s}^{-1}$, the plane-bed sample site (XS 7) has a lower $\tau_{\mathrm{b}}$ than the step-pool sample site (XS 24).

Critical shear stress differs between each of the sample sites largely because of differences in the median surface grain sizes (Table 3). The critical shear stress for the boulder step in the step-pool reach is $9-10$ times higher than for the other sampling sites. Excess shear stress $\left(\tau_{\mathrm{e}}{ }_{\mathrm{e}}=\tau_{\mathrm{b}} / \tau_{\mathrm{c}}\right) \geq 1$ and up to 4.5 indicate flows competent to partially (selectively) entrain site $D_{\max }$ grains. When $\tau^{*}{ }_{\mathrm{e}} \geq 4.5$, flows are suggested to result in full mobility of the $D_{\max }$ size fraction (Powell et al., 2001). At $Q_{\mathrm{bf}}$, planebed $D_{\max }$ grains remain stable while at the step-pool site $D_{\text {max }}$ grains may be partially entrained. Events exceeding $Q_{\text {bf }}\left(\right.$ i.e. $Q \geq 5.5 \mathrm{~m}^{3} \mathrm{~s}^{-1}$ ) are competent to partially entrain $D_{\text {max }}$ grains for the plane-bed and step-pool sample sites. $\tau^{*}{ }_{\mathrm{e}}$ based on the 1971 flood peak suggests full mobility of $D_{\max }$ grains at the plane-bed sites. The step-pool sample sites approach an $\tau^{*}$ e threshold for full mobility, however the downstream boulder remains stable and prevents the step-pool channel from shifting from Phase II to Phase III transport.

Table 2

Estimated flood hydrology for the study channel and modelled total boundary shear stress acting over the channel bed at OSL sampling locations

\begin{tabular}{lllllll}
\hline Flood & $\begin{array}{l}\text { Peak discharge } \\
\left(\mathrm{m}^{3} \mathrm{~s}^{-1}\right)\end{array}$ & $\begin{array}{l}\text { Mannings } n \\
\text { plane-bed }\end{array}$ & $\begin{array}{l}\text { Mannings } n \\
\text { step-pool }\end{array}$ & $\begin{array}{l}\tau_{\mathrm{b}} \mathrm{XS} 7 \mathrm{P} 1 \text { and P2 } \\
\left(\mathrm{Nm}^{-2}\right)\end{array}$ & $\begin{array}{l}\tau_{\mathrm{b}} \text { XS 24 S1 and S2 } \\
\left(\mathrm{Nm}^{-2}\right)\end{array}$ & $\begin{array}{l}\tau_{\mathrm{b}} \text { XS 23 Step } \\
\left(\mathrm{Nm}^{-2}\right)\end{array}$ \\
\hline Bankfull & $2.55(1-4.5)$ & $0.067(0.075-0.063)$ & $0.086(0.092-0.082)$ & $79(53-103)$ & $127(60-175)$ & $351(287-392)$ \\
Feb 2002 & 4.9 & 0.062 & 0.081 & 107 & 181 & 394 \\
Nov 1995 & 5.5 & 0.062 & 0.081 & 114 & 192 & 404 \\
Jun 1998 & 6.7 & 0.062 & 0.080 & 128 & 207 & 417 \\
Mar 2000 & 13.4 & 0.064 & 0.075 & 212 & 236 & 450 \\
1971 flood & 78.1 & 0.054 & 0.065 & 541 & 400 & 620 \\
\hline
\end{tabular}




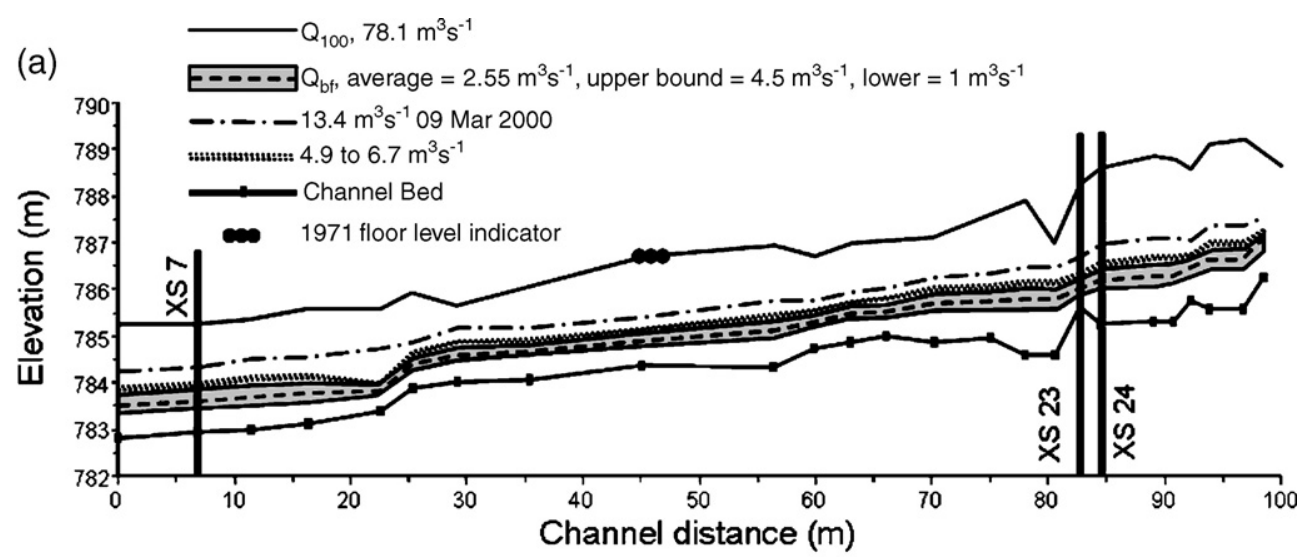

(b)

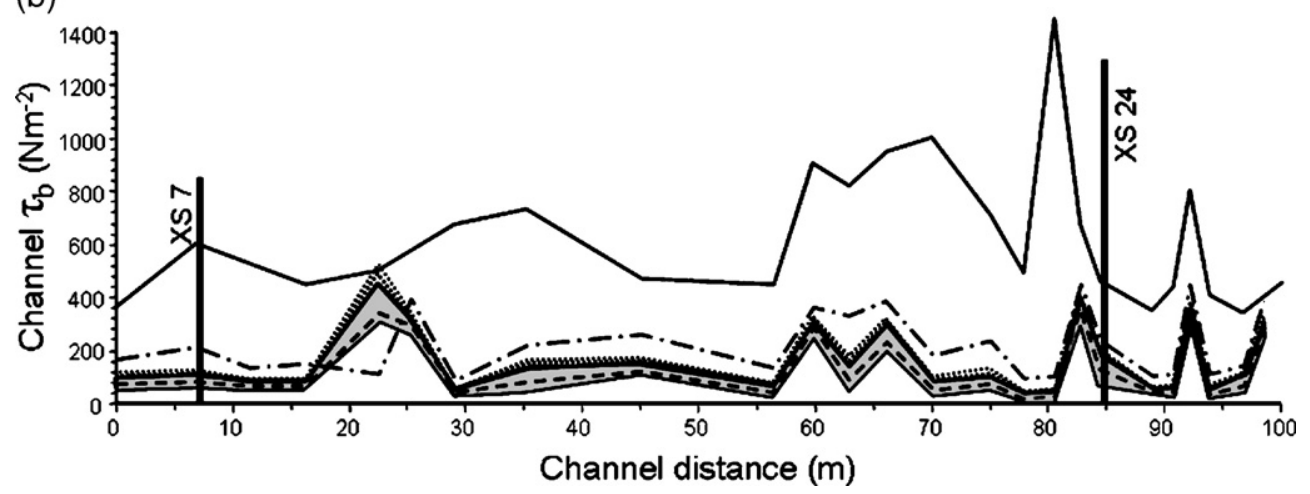

Fig. 9. HEC-RAS results. (a) Water surface profiles based on the estimated discharges and (b) the respective boundary shear stresses for the channel (excluding overbank areas).

Based on the applied competence equations, recent floods (e.g. November 1995, June 1998 or March 2000) are capable of mobilising the surface grain sizes at the plane-bed and pool area of the step-pool sites whereas the step particles remain immobile even for the 1971 flood.

\subsection{Quartz zeroing during fluvial transport}

Fig. 10a and $\mathrm{b}$ show single grain OSL distributions for the modern samples. Both samples show some variation in the values measured, with negative and positive $D_{\mathrm{e}}$ values observed. Both samples show a distribution, however, which is strongly peaked at zero age, demonstrating that the OSL signals of these samples had been well zeroed by light during transport in the natural environment. Fig. 10c shows the distribution of single grain ages measured (solid line), and for comparison, a Gaussian distribution centred on 1.99 Gy (dotted line) having a similar standard deviation to that of the lower part of the measured distribution. This lower peak is offset from the correct dose by a dose value corresponding to an age of around 15 years, strongly

Table 3

Critical $\left(\tau_{\mathrm{c}}\right)$ and excess shear stress $\left(\tau_{\mathrm{e}}{ }_{\mathrm{e}}=\tau_{\mathrm{b}} / \tau_{\mathrm{c}}\right)$ at OSL sampling locations and boulder step

\begin{tabular}{llllll}
\hline & P1 & P2 & S1 & S2 & Step \\
\hline $\begin{array}{l}\tau_{\mathrm{c}}\left(\mathrm{Nm}^{-2}\right) \\
\begin{array}{c}\tau_{e}^{*} \\
\text { Bankfull }\end{array}\end{array}$ & 108 & 115 & 85 & 105 & 970 \\
Feb 2002 & $0.73(0.51-0.98)$ & $0.68(0.47-0.92)$ & $1.50(0.67-1.96)$ & $1.20(0.57-1.66)$ & $0.36(0.30-0.40)$ \\
Nov 1995 & 0.99 & 0.93 & 2.14 & 1.72 & 0.41 \\
Jun 1998 & 1.05 & 0.99 & 2.26 & 1.82 & 0.42 \\
Mar 2000 & 1.19 & 1.12 & 2.44 & 1.97 & 0.43 \\
$1971 Q_{100}$ flood & 1.95 & 1.83 & 2.78 & 2.24 & 0.46 \\
\hline
\end{tabular}


suggesting that OSL for a quartz single grain is capable of returning reliable dose estimates.

\subsection{OSL dates from step-pool and plane-bed sites}

Between $70 \%$ and $90 \%$ of the quartz grains measured produced an observable OSL decay above background. Measurable grains ranged from 12 to 4300 counts in the initial $0.5 \mathrm{~s}$ OSL window, which is equivalent to 850 to $290,000 \mathrm{c}^{-1} \mathrm{~s}^{-1} \mathrm{mg}^{-1} \mathrm{~Gy}^{-1}$.

Table 4 summarises the ages of the youngest grains within the plane-bed and step-pool samples. Shallow samples S1S and P1S from both channel morphologies give mean ages coincidental with the 1971 flood. S2S, which is closer to the step than S1S, (Fig. 7b), however, has an age preceding the 1971 flood. P2S on the other hand contains grains likely deposited in the most recent sediment transporting event, possibly February 2002 or March 2000. The large $1 \sigma$ standard error in our results for the S1S and P1S samples suggest that these sediments could also be coincidental with the most recent sediment transporting events.

All deep samples, taken from between 350 and $500 \mathrm{~mm}$ below the surface, are older than respective overlying

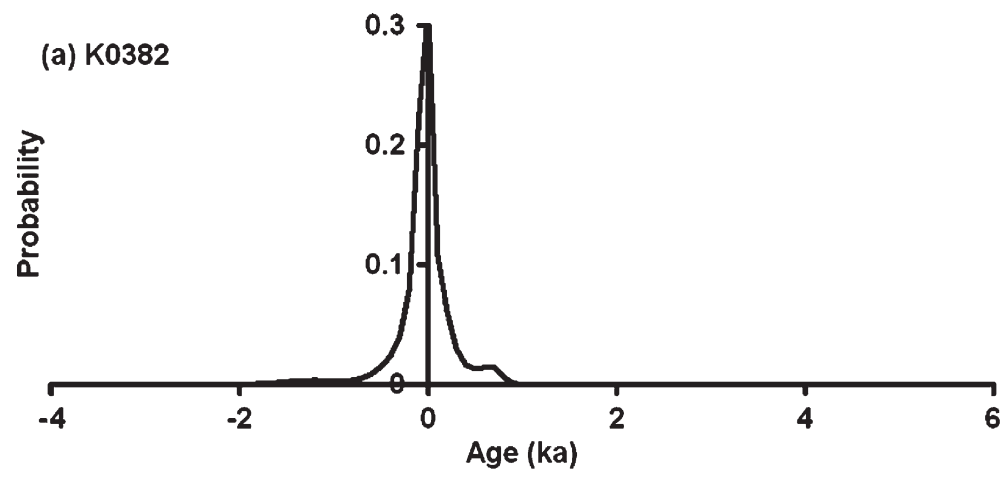

(b) $\mathrm{K} 0384$
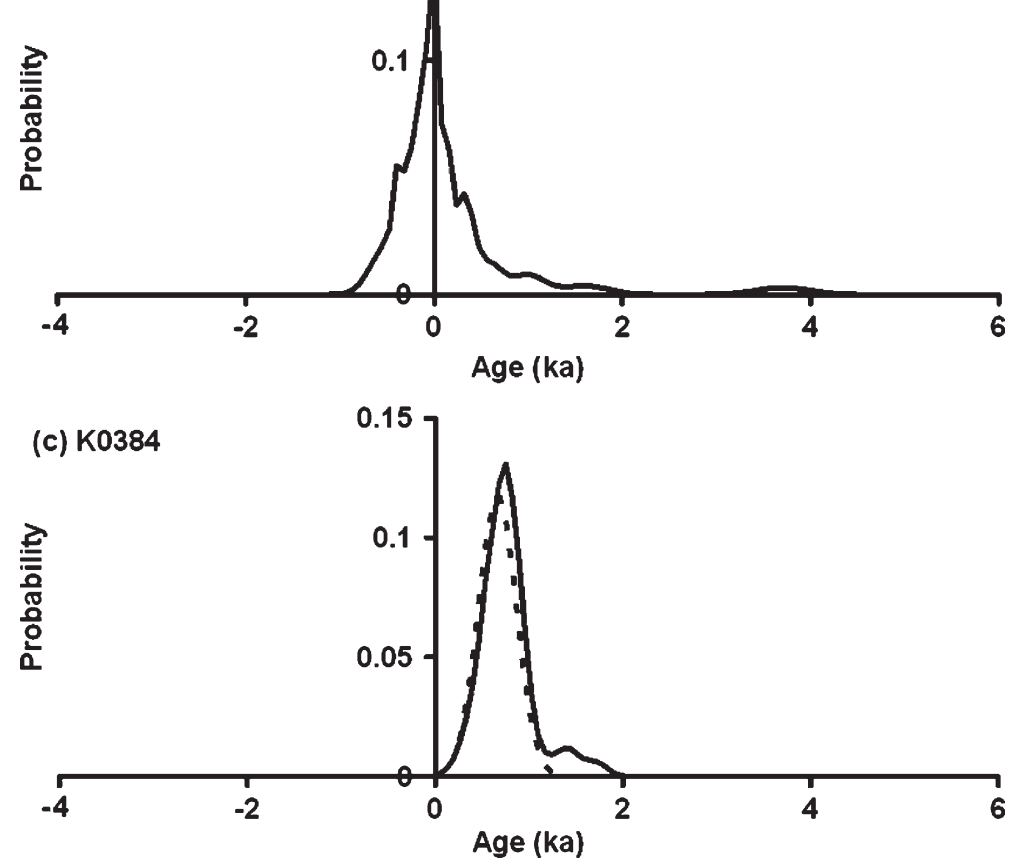

Fig. 10. Distributions of single grain OSL ages plotted as probability distribution functions for (a) modern sample K0382 (un-named creek), (b) modern sample K0384 (Oldroad Ck.), showing good natural zeroing of the OSL signal, and (c) solid line: sample K0384 after the addition of a beta dose of 1.99 Gy (equivalent to 660 years); dotted line: Gaussian distribution centred at 1.99 Gy, with approximately the same width as the lower distribution of sample K0384. The very small discrepancy between these two curves demonstrates the suitability of the quartz in this region for reliable estimation of single grain OSL ages. 
Table 4

Measured K, Th and $\mathrm{U}$ concentrations, gamma plus cosmic and total dose rates, minimum age model equivalent dose $\left(D_{\mathrm{e}}\right)$ values and minimum age model age estimates for Genoa River, NSW, single grain samples

\begin{tabular}{|c|c|c|c|c|c|c|c|c|c|}
\hline $\begin{array}{l}\text { Field } \\
\text { code }\end{array}$ & $\begin{array}{l}\text { Lab. } \\
\text { code }\end{array}$ & $\mathrm{K}(\%)$ & Th (ppm) & $\mathrm{U}(\mathrm{ppm})$ & $\begin{array}{l}\text { Gamma }+ \text { cosmic } \\
\text { dose rate }(m G y / a)\end{array}$ & $\begin{array}{l}\text { Total dose } \\
\text { rate (mGy/a) }\end{array}$ & $\begin{array}{l}\text { Minimum age } \\
\text { model } D_{\mathrm{e}}(\mathrm{Gy})\end{array}$ & $\begin{array}{l}\text { Age (years } \\
\text { before AD 2005) }\end{array}$ & Age (year AD) \\
\hline S1S & K0385 & $2.71 \pm 0.12$ & $13.2 \pm 0.6$ & $3.08 \pm 0.18$ & $1.51 \pm 0.05$ & $3.38 \pm 0.17$ & $0.12 \pm 0.12$ & $35 \pm 35$ & $1970(1935-2005)$ \\
\hline S1D & K0386 & $2.71 \pm 0.12$ & $13.2 \pm 0.6$ & $3.08 \pm 0.18$ & $1.46 \pm 0.02$ & $3.33 \pm 0.16$ & $0.60_{-0.40}^{+0.20}$ & $180_{-120}^{+60}$ & $1825(1765-1945)$ \\
\hline S2S & K0387 & $2.44 \pm 0.11$ & $13.2 \pm 0.6$ & $3.09 \pm 0.18$ & $1.51 \pm 0.05$ & $3.24 \pm 0.16$ & $0.45 \pm 0.06$ & $140 \pm 20$ & $1865(1845-1885)$ \\
\hline P1S & K0388 & $2.26 \pm 0.10$ & $11.0 \pm 0.5$ & $2.79 \pm 0.16$ & $1.29 \pm 0.04$ & $2.86 \pm 0.14$ & $0.11_{-0.51}^{+0.20}$ & $40_{-180}^{+70}$ & $1965(1895-2005)$ \\
\hline P1D & K0389 & $2.04 \pm 0.09$ & $10.9 \pm 0.5$ & $2.42 \pm 0.15$ & $1.25 \pm 0.02$ & $2.68 \pm 0.13$ & $0.21_{-0.09}^{+0.05}$ & $80_{-35}^{+20}$ & $1925(1905-1960)$ \\
\hline $\mathrm{P} 2 \mathrm{~S}$ & K0390 & $2.30 \pm 0.11$ & $12.6 \pm 0.6$ & $2.82 \pm 0.17$ & $1.36 \pm 0.05$ & $2.98 \pm 0.15$ & $-0.06_{-0.24}^{+0.12}$ & $\begin{array}{r}-20_{-80}^{+40} \\
-40\end{array}$ & $2005(1985-2005)$ \\
\hline $\mathrm{P} 2 \mathrm{D}$ & K0391 & $1.93 \pm 0.09$ & $10.9 \pm 0.5$ & $2.98 \pm 0.17$ & $1.22 \pm 0.02$ & $2.64 \pm 0.12$ & $0.12 \pm 0.01$ & $45 \pm 5$ & $1950(1955-1965)$ \\
\hline
\end{tabular}

All uncertainties are measured or calculated 1 sigma standard errors, and age estimates are quoted in years before AD 2005. Note the asymmetric uncertainties produced by the minimum age model for samples K0386, K0388, K0389 and K0390, which leads to asymmetric age estimates for these samples.

grains and are dated to precede the 1971 flood. No differences in the minimum age estimates of the deep samples exist between the plane-bed and step-pool samples.

Frequency distributions for the combined shallow samples (S1S, S2S, P1S, P2S) indicate multimodal age distributions, of 100, 700 and 1400 years before AD 2005 (Fig. 11a). Combined single grain ages for the deep samples (S1D, P1D, P2D) also indicates multimodal age distributions (Fig. 11b) of 100, 400 and 700 years before AD 2005. The majority of grains in the shallow and deep samples indicate significantly older age estimates, suggesting matrix sediment which has remained stored for $100 \mathrm{~s}$ to $1000 \mathrm{~s}$ of years.

\section{Discussion}

\subsection{Influence of bedforms}

This study investigated the nature of residency of fine sediments in two mountain channel morphologies using a
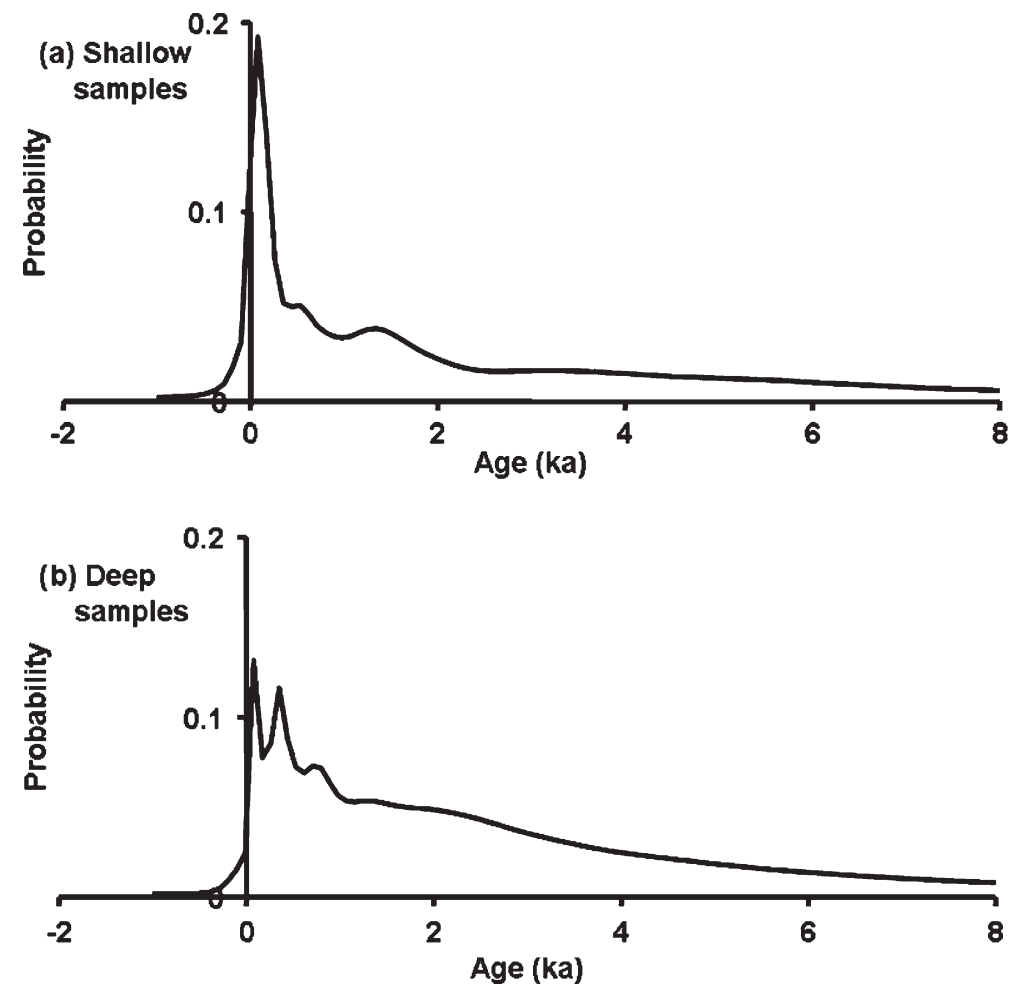

Fig. 11. Distributions of single grain OSL ages plotted as probability distribution functions for (a) buried sample K0385 (S1S) and (b) buried sample K0388 (P1S). Both samples show well defined multiple peaks in depositional ages. 
combined approach of hydraulic modelling and OSLderived estimates of age of mineral quartz in shallow and deep subsurface material. Model predictions indicate that moderate discharges (between bankfull and 13-yr events) are required to mobilise the maximum overlying surface grain sizes at both sites. Flood discharges greater than 100 years are required where the boulder step influences channel stability. Similar ranges of mobilities in step-pool channels influenced by step particles are reported in Chin (1998). The OSL derived minimum ages from quartz in the shallow bed depths of the two reaches concord with these model predictions. The minimum ages from the deep bed samples for both the planebed and step-pool reaches exceed the date of the 100 year flood. These dates also support conclusions from previous work where sediment exchange limits for competent discharges approach twice the depth of the surface $D_{90}$ grain size (Wilcock and McArdell, 1997; DeVries, 2002).

Minimum ages for the shallow samples from the planebed sites are similar, whereas, significant age differences are observed between the shallow samples for the pool section of the step-pool reach. This implies some influence of the downstream step. Wohl and Thompson (2000) report velocity data which shows that relatively steady and uniform flow with high near-bed velocities occurs over planebeds in contrast to the deceleratingaccelerating flow, wake turbulence and mid-profile shear sequence which occurs as flow approaches, passes over steps and plunges into pools. They also suggested that velocity profiles below pools, but above the influence of a step, are similar to the velocity profiles over planebeds. This may explain the similarity in the minimum ages between the planebed and the furthest upstream of the step-pool sites. OSL data shows that while the planebed has a lower gradient than the step-pool reach, both morphologies exchange bed material to a similar depth during similar sized floods. The spatial extent of this exchange, however, appears to be restricted in the step-pool site by velocity and shear changes which occur because of the step bedform.

Interpreting the significance of the role of the step in stabilising the step-pool reach is not straight forward. Steps have been reported to influence rates of bed load for high frequency events ( $\leq 5$ y return interval) (Whittaker, 1987), but are thought to have a negligible role in regulating bed load transport in low frequency $(\geq 100 \mathrm{y}$ ARI) high magnitude floods (Warburton, 1992). In this study, the step appears to have some upstream influence on surface stability during floods up to the 100 year return interval. For example, the youngest grains at S2S are significantly older than the 1971 flood, whereas, a meter upstream at S1S, grain burial ages are coincident with at least the 1971 flood, or possibly even the more recent events that just exceeded bankfull discharge and are similar to the planebed samples.

\subsection{Bed material storage}

Previous studies have indicated a threshold discharge above which surface armour grains are mobilised, allowing the release of trapped finer particles in the bed during Phase II and III transport (Warburton, 1992; Ryan et al., 2005). The uncertainty associated with the OSL ages means we are unable to quantify thresholds of mobility. OSL specifically measures the time since deposition which may not always coincide with the latter phases of transport as predicted by the competence equations. Whereas Phase II and III transport allows the remobilisation of trapped sediment to supply downstream beds, Phase I transport can also supply sediment from pool fills, gullies or hillslope erosion. This sediment can move into, and percolate down through, the channel bed depending on sediment size and pore dimensions (Frostick et al., 1984). When individual pores become clogged, sediment can still permeate downwards by moving through unclogged interstices until complete blockage occurs and the bed starts filling surface-wards (Frostick et al., 1984). The presence, and importantly the preservation, of multiple modal populations of grains indicates the inclusion of fine particles that relate to earlier episodes of sediment transport. Subsequent discharge events have not been capable of completely flushing finebed sediment from the upper sample layer and the bottom sample depth. One possible scenario, therefore, is that recent sub-bankfull discharges are responsible for delivering fine sediment to the channel bed (Phase I transport) which permeates into the sub-armour layer. It is possible that the mobilised sediment infilled the channel bed pores to greater depths than can be flushed, even by floods capable of producing full mobility of the surface grains (e.g.1971 flood). Overall, the data confirms that the exchange of fine-bed material occurs regularly (annual to decade scale) but that sediment residency approaches hundreds of years with evidence of pulses of activity every few hundred years.

\subsection{Use of hydraulic modelling and competence equations}

Interpretation of these results are influenced by two important considerations: (1) the accuracy of the hydraulic modelling and competence equations; (2) the reliability and interpretation of the estimates of OSLderived ages. In relation to the first issue, many factors 
such as grain shape, orientation and packing, may affect predicted shear stresses. As a result, a suite of competence equations have been developed to accommodate these influences in mountain streams. A detailed review and comparison of the relevant equations were undertaken prior to the selection of Komar's equation. In addition, this equation performed well when compared to actual data of sediment transport in the study channel. For example, in July 2005 a flow exceeding $Q_{\text {bf }}$ was recorded by site instrumentation (depth loggers and bed load traps) with an estimated discharge of $5.5 \mathrm{~m}^{3} \mathrm{~s}^{-1}$ (HEC-RAS). Based on the largest grain collected in Birkbeck-slot traps, the predicted $\tau{ }^{*}$ for the July 2005 event was 1.2. Applying alternative equations, such as Costa's (1983) lower envelop curve or a smaller value of $\tau^{*}{ }_{\text {c50 }}$ (e.g. 0.045 by Olsen et al., 1997), grain sizes of $\sim 835-1286 \mathrm{~mm}$ are predicted to be mobilised, $4-6$ times larger than present in the bed load traps. The model used in this study, therefore, represents the best available prediction of sediment entrainment for the site characteristics studied in the Log Culvert Creek Catchment.

\subsection{Integrity of OSL-derived ages}

In relation to the second limitation on interpreting the estimates of OSL ages, several issues need to be considered. Whereas luminescence dating has been applied to a wide variety of depositional environments (Stokes, 1999), its application to the dating of fluvial deposits has raised issues regarding the completeness of bleaching or zeroing of trapped charge during sediment transport. Incomplete or partial bleaching invalidates the assumption that the population of quartz grains has a zero age at time of deposition, which can lead to significant overestimation of age (Wallinga, 2002). Rhodes and Pownall (1994) illustrate some of these problems for quartz grains from recent sediments collected in the geomorphologically-active Himalaya region, later supported by the observations of Rhodes and Bailey (1997) and Rhodes (2000). This work suggests that newlyweathered quartz may require several deposition cycles to 'condition' the luminescence properties and enable complete zeroing of charge. Light attenuation by water depth, turbidity, and thickness of bed load may also prevent homogenous populations of zeroed grains at deposition. Whilst acknowledging these issues, results from our zeroing experiments on the modern samples clearly indicate that no inherent problems occur with quartz in this environment. Definitive values of the mean burial ages will, however, be limited by the range of $1 \sigma$ standard errors. Although comparable to those reported in Olley et al. (2004) and Rodnight et al. (2005), they do prevent definitive interpretation of some of the results of minimum ages with respect to specific flows.

\section{Conclusions}

Two channel sites with contrasting morphologies were studied to investigate the storage time of fine-grained material in mountain streams, which are traditionally difficult to monitor during infrequent high discharges. Results indicate that recurrence interval floods exceeding bankfull, and up to 13 years, are competent to mobilise the maximum overlying surface grain sizes at step-pool and plane-bed sites. OSL minimum age model results of well bleached quartz in the fine matrix particles indicate general agreement with selected competence equations. The apparent long burial age of most of the mineral quartz, however, suggests that competent flows are not able to completely flush all subsurface fine-bed material. The maximum depth of bed load exchange (flushing) was limited to twice the depth of the overlying $D_{90}$ grain size. Steps may have limited spatial control on bed load exchange from shallow depths.

Overall, this study has demonstrated the applicability of the OSL technique to determining sediment mobility in mountain streams. The bleaching experiments undertaken in this study confirm that no inherent problems occur with the quartz material and OSL provides a practical technique in deriving meaningful ages of burial. This technique, therefore, holds considerable promise for future applications.

\section{Acknowledgements}

This work was supported by a UNSW Faculty Research Grant awarded to Jacky Croke and Chris Thompson. Simon Mockler and Merv Thompson are thanked for their field assistance and Norman Hill for the OSL sample preparation. Forests New South Wales provided access to the catchment. New South Wales Department of Infrastructure, Planning and Natural Resources and the Victorian Water Resources Data Warehouse provided instantaneous discharge data for the Genoa River. Brian Humphreys provided rainfall records for Craigie weather station. We thank Anne Chin and two anonymous reviewers for their comments on the manuscript.

\section{References}

Adamiec, G., Aitken, M.J., 1988. Dose-rate conversion factors: update. Ancient TL 16, 37-50.

Aitken, M.J., 1985. Thermoluminescence Dating. Academic Press Inc. Ltd., London. 359 pp. 
Banerjee, D., Murray, A.S., Bøtter-Jensen, L., Lang, A., 2001. Equivalent dose estimation using single aliquot of polymineral fine grains. Radiation Measurements 33, 73-94.

Buffington, J.M., Montgomery, D.R., 1997. A systematic analysis of eight decades of incipient motion studies, with special reference to gravel-bedded rivers. Water Resources Research 33 (8), 1993-2029.

Carling, P.A., 1988. The concept of dominant discharge applied to two gravel-bed streams in relation to channel stability thresholds. Earth Surface Processes and Landforms 13, 355-367.

Chin, A., 1998. On the stability of step-pool mountain streams. Journal of Geology 106, 59-69.

Chin, A., 2003. The geomorphic significance of step-pools in mountain streams. Geomorphology 55, 125-137.

Church, M., Hassan, M.A., Wolcott, J.F., 1998. Stabilizing selforganized structures in gravel-bed stream channels: field and experimental observations. Water Resources Research 34 (11), 3169-3179.

Costa, J.E., 1983. Paleohydraulic reconstruction of flash-flood peaks from boulder deposits in the Colorado Front Range. Geological Society of America Bulletin 94, 986-1004.

DeVries, P.E., 2002. Bedload layer thickness and disturbance depth in gravel bed streams. Journal of Hydraulic Engineering 128 (11), 983-991.

Emmett, W.W., Wolman, M.G., 2001. Effective discharge and gravelbed rivers. Earth Surface Processes and Landforms 26, 1369-1380.

Erskine, W., 1993. Erosion and deposition produced by a catastrophic flood on the Genoa River, Victoria. Australian Journal of Soil and Water Conservation 6 (4), 35-43.

Frostick, L.E., Lucas, P.M., Reid, I., 1984. The infiltration of fine matrices into coarse-grained alluvial sediments and its implications for stratigraphical interpretation. Journal of the Geological Society (London) 141, 955-965.

Fuchs, M., Lang, A., 2001. OSL dating of coarse-grain fluvial quartz using single-aliquot protocols on sediments from NE Peloponnese, Greece. Quaternary Science Reviews 20 (5-9), 783-787

Galbraith, R.F., Roberts, R.G., Laslett, G.M., Yoshida, H., Olley, J.M., 1999. Optical dating of single and multiple grains of quartz from Jinmium rock shelter, northern Australia: Part I. Experimental design and statistical models. Archaeometry 41, 339-364.

Gordon, N.D., McMahon, T.A., Finlayson, B.L., Gippel, C.J., Nathan, R.J., 2004. Stream Hydrology, An Introduction for Ecologists. Wiley, Chichester. $221 \mathrm{pp}$.

Grant, G.E., Swanson, F.J., Wolman, M.G., 1990. Pattern and origin of stepped-bed morphology in high gradient streams, Western Cascades, Oregon. Geological Society of America Bulletin 102, 340-352.

Haschenburger, J.K., Wilcock, P.R., 2003. Partial transport in a natural gravel bed channel. Water Resources Research 39 (1), 1020. doi:10.1029/2002WR001532.

Jackson, W.L., Beschta, R.L., 1982. A model of two-phase bedload transport in an Oregon range stream. Earth Surface Processes and Landforms 7, 517-527.

Jarrett, R.D., 1984. Hydraulics of high-gradient streams. ASCE Journal Hydraulics Division 110, 1519-1539.

Komar, P.D., 1989. Flow-competence evaluations of the hydraulic parameters of floods: an assessment of the technique. In: Beven, K., Carling, P.A. (Eds.), Floods. Hydrological, Sedimentological and Geomorphological Implications. John Wiley and Sons, Chichester, pp. 107-134.
Komar, P.D., Li, Z., 1986. Pivoting analyses of the selective entrainment of sediments by shape and size with application to gravel threshold. Sedimentology 33, 425-436.

Laronne, J.B., Carson, M.A., 1976. Interrelationships between bed morphology and bed-material transport for a small, gravel-bed channel. Sedimentology 23, 67-85.

Laronne, J.B., Outhet, D.N., Carling, P.A., McCabe, T.J., 1994. Scour chain employment in gravel bed rivers. Catena 22, 299-306.

Lenzi, M.A., Mao, L., Comiti, F., 2004. Magnitude-frequency analysis of bed load data in an alpine boulder bed stream. Water Resources Research 40, W07201. doi:10.1029/2003WR002961.

Limerinos, J.T., 1970. Determination of the Manning coefficent from measured bed roughness in natural channels. U.S. Geological Survey Water-Supply Paper 1898-B, Federal Centre, Colo.

Mejdahl, V., 1979. Thermoluminescence dating: beta dose attenuation in quartz grains. Archaeometry 21, 61-73.

Murray, A.S., Wintle, A.G., 2000. Luminescence dating of quartz using an improved single-aliquot protocol. Radiation Measurements 32, $57-73$.

Olley, J.M., Caitcheon, G.G., Murray, A.S., 1998. The distribution of apparent dose as determined by optically stimulated luminescence in small aliquots of fluvial quartz: implications for dating young sediments. Quaternary Geochronology 17, 1033-1040.

Olley, J.M., Pietsch, T., Roberts, R.G., 2004. Optical dating of Holocene sediments from a variety of geomorphic settings using single grains of quartz. Geomorphology 60, 337-358.

Olsen, D.S., Whitaker, A.C., Potts, D.F., 1997. Assessing stream channel stability thresholds using flow competence estimates at bankfull stage. Journal of the American Water Resources Association 33 (6), 1197-1207.

Petit, F., 1994. Dimensionless critical shear stress evaluation from flume experiments using different gravel beds. Earth Surface Processes and Landforms 19, 565-576.

Petit, F., Gob, F., Houbrechts, G., Assani, A.A., 2005. Critical specific stream power in gravel-bed rivers. Geomorphology 69 (1-4), 92-101.

Powell, D.M., Reid, I., Laronne, J.B., 2001. Evolution of bed load grain size distribution with increasing flow strength and the effect of flow duration on the caliber of bed load sediment yield in ephemeral gravel bed rivers. Water Resources Research 37 (5), 1463-1474.

Prescott, J.R., Hutton, J.T., 1994. Cosmic ray contributions to dose rates for luminescence and ESR dating: large depths and long term time variations. Radiation Measurements 23, 497-500.

Reinson, G.E., 1977. Hydrology and Sediments of a Temperate Estuary - Mallacoota Inlet, Victoria, vol. 178. Australian Government Publishing Service. 91 pp.

Rodnight, H., Duller, G.A.T., Tooth, S., Wintle, A.G., 2005. Optical dating of a scroll-bar sequence on the Klip River, South Africa, to derive the lateral migration rate of a meander bend. The Holocence 15 (6), 802-811.

Rhodes, E.J., 1988. Methodological considerations in the optical dating of quartz. Quaternary Science Reviews 7, 395-400.

Rhodes, E.J., 2000. Observations of thermal transfer OSL signals in glacigenic quartz. Radiation Measurements 32, 595-602.

Rhodes, E.J., Bailey, R.M., 1997. The effect of thermal transfer on the zeroing of the luminescence of quartz from recent glaciofluvial sediments. Quaternary Science Reviews 16 (3-5), 291-298.

Rhodes, E.J., Pownall, L., 1994. Zeroing of the OSL signal in quartz from young glaciofluvial sediments. Radiation Measurements 23 (2/3), 581-585.

Rhodes, E.J., Bronk-Ramsey, C., Outram, Z., Batt, C., Willis, L., Dockrill, S., Bond, J., 2003. Bayesian methods applied to the 
interpretation of multiple OSL dates: high precision sediment age estimates from Old Scatness Broch excavations, Shetland Isles. Quaternary Science Reviews 22, 1231-1244.

Ryan, S.E., Porth, L.S., Troendle, C.A., 2002. Defining phases of bedload transport using piecewise regression. Earth Surface Processes and Landforms 27, 971-990.

Ryan, S.E., Porth, L.S., Troendle, C.A., 2005. Coarse sediment transport in mountain streams in Colorado and Wyoming, USA. Earth Surface Processes and Landforms 30, 269-288.

Spencer, J.Q., Owen, L.A., 2004. Optically stimulated luminescence dating of late Quaternary glaciogenic sediments in the upper Hunza valley: validating the timing of glaciation and assessing dating methods. Quaternary Science Reviews 23, 175-191.

Stokes, S., 1999. Luminescence dating applications in geomorphological research. Geomorphology 29 (1-2), 153-171.

US Army Corps of Engineers, H.E.C., 2003. HEC-RAS 3.1.1.

Wallinga, J., 2002. Optically stimulated luminescence dating of fluvial deposits: a review. Boreas 31, 303-322.

Warburton, J., 1992. Observations of bed load transport and channel bed changes in a proglacial mountain stream. Arctic and Alpine Research 24 (3), 195-203.

Whittaker, J.G., 1987. Modelling bed-load transport in steep mountain streams. In: Beschta, R.L., Blinn, T., Grant, G.E., Ice, G.G.,
Swanson, F.J. (Eds.), Erosion and Sedimentation in the Pacific Rim. IAHS Press, Wallingford, pp. 319-332.

Wilcock, P.R., McArdell, B.W., 1997. Partial transport of a sand/gravel sediment. Water Resources Research 33 (1), 235-245.

Wilcock, P.R., Kondolf, G.M., Mathews, W.V.G., Barta, A.F., 1996a. Specification of sediment maintenance flows for a large gravel-bed river. Water Resources Research 32 (9), 2911-2921.

Wilcock, P.R., Barta, A.F., Shea, C.C., Kondolf, G.M., Matthews, W.V.G., Pitlick, J., 1996b. Observations of flow and sediment entrainment on a large gravel-bed river. Water Resources Research 32 (9), 2897-2909.

Wohl, E.E., Thompson, D.M., 2000. Velocity characteristics along a small step-pool channel. Earth Surface Processes and Landforms 25 (4), 353-367.

Young, W.J., Ogden, R.W., Hughes, A.O., Prosser, I.P., 2002. Predicting channel type from catchment and hydrological variables. In: Dyer, F., Thoms, M., Olley, J.M. (Eds.), The Structure Function and Management Implications of Fluvial Sedimentary Systems. IAHS Press, Wallingford, pp. 53-60.

Zimmermann, A., Church, M., 2001. Channel morphology, gradient profiles and bed stresses during flood in a step-pool channel. Geomorphology 40, 311-327. 